\title{
Clarifying the Functions of Social Support in Later Life
}

\author{
NEAL KRAUSE \\ ELAINE BORAWSKI-CLARK \\ University of Michigan
}

\begin{abstract}
Research on the stress-buffering properties of social support contains a number of contradictory findings. At least part of this problem may be attributed to the fact that researchers have not developed a well-articulated theory explaining how social support functions in later life. Based on recent developments in identity theory, evidence is presented which suggests that emotional support tends to reduce the deleterious effects of some types of stress (i.e., events arising in salient social roles) but not others (i.e., stressors that emerge in roles that are valued less highly). This theoretical framework is extended by showing that social support operates at least in part by bolstering feelings of control and self-worth that have been eroded by stressful experiences. However, the data indicate that these beneficial effects are restricted to feelings of control and self-esteem that are associated with the same roles in which the stressors emerged.
\end{abstract}

After decades of research, the literature on the stress-buffering properties of supportive social relationships still contains contradictory findings. Although some investigators report that assistance from significant others tends to buffer or offset the deleterious effects of stress, other researchers have been unable to observe similar effects (see George 1989 for a review of this research). Although there are

AUTHORS'NOTE: This research is supported by two grants from the National Institute on Aging (RO1-AG09221; RO1-AG08491; Neal Krause, Principal Investigator). Reprint requests should be addressed to Neal Krause, Department of Health Behavior and Health Education, School of Public Health, The University of Michigan, 1420 Washington Heights, Ann Arbor, MI 48109-2029. 
many reasons for these inconsistencies, at least part of the problem arises from the fact that the theoretical foundations of the social support process have not been articulated fully. To make sense of the work that has been done so far, researchers need to know more about how assistance provided by social network members helps older adults to cope effectively with the noxious impact of stressful life events.

One line of reasoning suggests that stress affects well-being indirectly by eroding feelings of personal control and self-worth (e.g., Pearlin, Menaghan, Lieberman, and Mullan 1981). Moreover, this perspective further specifies that social support may offset these negative effects by replenishing the very resources (i.e., feelings of self-worth and control) that have been depleted by these stressful experiences (Krause 1987a, 1987b). Taken together, this literature indicates that researchers interested in learning more about the stress process may benefit by attempting to further illuminate the nature of linkages among these potentially important intervening constructs. It is primarily for this reason that the analyses presented below will focus exclusively on the relationships among stress, social support, feelings of control, and self-esteem.

Although the studies described above have provided some useful insights, this research has failed to keep pace with important developments in the broader social psychological literature. In particular, a number of investigators have argued that the construct of control is not a unidimensional phenomenon and that older adults may feel as though they exercise more control in some areas of life than in others (e.g., Schulz, Heckhausen, and Locher 1991). Similarly, the wide majority of studies in the stress field that examine feelings of selfworth focus exclusively on global measures even though social psychologists have argued for some time that the self is composed of multiple identities that are linked to the roles that older adults occupy (see Bengtson, Reedy, and Gordon 1985 for a review of this research). What is needed at this point is a theoretical framework that will enable researchers to take advantage of the advances in the conceptualization and assessment of personal control and self-esteem. The purpose of this study is to take a modest first step toward this goal by showing how recent developments in identity theory can be used to clarify the relationships among stressful events, social support, feelings of control, and feelings of self-worth in later life. 
The discussion that follows is divided into four parts. First, the conceptual underpinnings of identity theory are described and extended. Following this, the nationwide sample and study measures that are used to evaluate these theoretical specifications are presented. The data analysis strategy is reviewed next. Finally, the study results are presented and discussed.

\section{Clarifying the Social Support Process}

Recent extensions of identity theory provide a useful point of departure for developing a more focused view of the functions of social support in later life (Thoits 1987; Burke 1991). Social roles and the identities associated with these roles form the core of this theoretical perspective. A social role is defined structurally as a position in a group (e.g., a father or husband) whereas an identity is a self-evaluation that emerges from occupying these roles (e.g., when a person accepts the fact that he is a father and begins to think of himself in this way). Associated with each role are clusters of norms and behavioral expectations that provide a basis for determining whether performance in a given role is adequate. These basic regulatory functions are thought to provide a sense of meaning and purpose in life. According to Thoits (1991), stressors arising in certain social roles may exert an especially deleterious effect because they have the potential to undermine the identity associated with that role. There is, however, one important stipulation.

Individuals occupy a number of different roles. According to the conceptual orientation developed here, there is a separate identity associated with each of these social positions. However, some roles are viewed as being more important than others, and as a result, some identities play a larger role in defining the self than others. In fact, a number of social psychologists have observed that individual identities are organized into a salience hierarchy reflecting varying levels of commitment to and emotional investment in the roles associated with these identities (see, for example, Stryker 1987).

Thoits (1991) and Burke (1991) maintain that if some roles are valued more highly than others, then the impact of stressors arising in various roles will depend on where these roles are located in the 
salience hierarchy. Stressors emerging in highly valued roles should have a more negative impact than events arising in roles that are valued less highly. Support for this theoretical perspective is provided in two recent papers by Krause (Krause forthcoming a, forthcoming b). The data in the first article suggest that whereas stressors arising in salient social roles tend to erode feelings of life satisfaction among older adults, similar effects are not observed with events arising in less highly valued roles. Perhaps more important, the findings from this study further reveal that salient role stressors tend to affect well-being by diminishing feelings of control that are associated with the same roles in which these salient stressors emerged (i.e., role-specific feelings of control). In contrast, a significant relationship was not observed between salient role stressors and a global measure of personal control.

The purpose of the second article was to examine the interrelationships among stress, social support, and diabetes (Krause forthcoming b). Two potentially important findings emerged from this research. First, consistent with identity theory perspective, stressors arising in salient social roles appear to be related more strongly to the odds of having diabetes than events arising in less important roles. Second, the data suggest that social support buffers the impact of salient role stressors but not the effects of events associated with roles that are valued less highly.

The analysis presented below aims to weave the findings from these articles together to form a more articulate and well-developed theory of how social support operates in later life. More specifically, the intent is to test the following rationale: If salient role stressors operate primarily by eroding role-specific feelings of control and if social support buffers the effects of salient role stressors (but not the effects of other life events), then perhaps the salubrious effects of supportive social ties may be traced to the possibility that assistance from others tends to bolster role-specific feelings of control. Building on previous research (Krause 1987a), another goal of the present study is to broaden the scope of inquiry by evaluating whether the same logic applies to role-specific feelings of self-worth. By examining the interface among stress, control, self-worth, and support in a rolespecific context, this study aims to provide a way to take full advantage of the rich conceptual insights that social psychologists have devel- 
oped on the structure of personal control and self-worth in later life (Schulz et al. 1991; Bengtson et al. 1985).

Before proceeding with the analyses, however, it is important to further develop the theoretical framework by briefly specifying why social support may be especially likely to replenish role-specific feelings of control and self-worth. Two lines of research that have developed in a largely independent manner provide a convenient point of departure for examining this issue. The first is reviewed by Eckenrode and Wethington (1990), and the second may be found in the work of Hobfoll (1989).

Eckenrode and Wethington (1990) note that when stressors arise, individuals will seek out assistance from others only after they are unable to resolve the problem on their own. Although the reasons for this finding are not clear, perhaps part of the explanation can be found by examining the norms surrounding the social support process. Social support is not an unlimited resource; significant costs may be incurred when repeated requests for assistance are made because potential support providers may begin to feel that they are being taken advantage of (see La Gaipa 1990 for a review of this research). Because of the potential costs associated with mobilizing assistance from others, elderly people must decide when to spend their social capital. However, the factors that influence this decision have not been described fully in the literature.

Fortunately, a potentially useful explanation may be found by extending the insights embedded in Hobfoll's (1989) theoretical work on the stress process (i.e., the conservation of resources perspective). He argues that people are especially motivated to actively confront the effects of life events that threaten things they value highly. By merging this observation with the work reviewed by Eckenrode and Wethington (1990), it may be possible to more clearly specify when older adults will turn to others for assistance. Whereas elderly people may be especially inclined to seek help when events arise in areas they value highly, they may be less willing to run the risk of encountering resentment or rejection by requesting assistance with events that arise in areas that are not as important to them. Perhaps more important, the potential benefits associated with receiving aid from others may be maximized when older adults receive assistance with events that arise in highly salient roles. To see why this may be true, it is important 
to more closely examine how assistance from others may increase feelings of personal control and self-esteem.

Social support is sometimes thought of as helping people to help themselves. This means that although others are willing to assist a person in need, they do not (or often cannot) do everything for them. Instead, support providers frequently give encouragement or other forms of emotional support but leave the main responsibility for confronting a problem with the stressed individual. Perhaps this is one reason why Krause and Markides (1990) observed that emotional support is provided to older adults more frequently than any other kind of assistance (i.e., than either tangible or informational support). By giving help in this way, the support provider may not feel overly burdened nor will the support recipient feel overly dependent upon them (Lee 1985). More important, feelings of control and self-worth are especially likely to be bolstered in this context because in the process of helping themselves, elderly people will come to feel as though they can control the course of events in their lives and that they are persons of worth (Caplan 1981). However, it is evident that under these circumstances, considerable effort may be required on the part of the stressed person. As a result, they must be highly motivated in order to see the problem situation through to the end. As the work of Hobfoll (1989) suggests, this kind of effort is more likely to be forthcoming when an event emerges in a role that is valued highly.

There is a second reason why support that is offered to confront salient role stressors is likely to be especially efficacious. Perhaps when salient stressors emerge, the heightened motivation on the part of the stressed individual is complemented by an added sensitivity on the part of the support provider. To see why this may be the case, it is important to consider how stress may affect the provision of supportive behaviors. A number of investigators subscribe to the resource mobilization perspective that states that increased exposure to stress is associated with greater support from significant others (see Krause 1989 for a review of this research). However, several investigators have recently begun to challenge this overly positive view of the social support process by suggesting that in some cases stress may elicit negative interaction from social network members as well as supportive behaviors (e.g., Krause and Liang forthcoming; Krause 1991). For 
example, this negative interaction may involve criticism or blame for playing a role in bringing about the stressful situation.

Perhaps support providers may be more willing to afford greater latitude to the stressed person when they are aware that these individuals are grappling with an event that is highly salient and that threatens core elements in their identity. Instead of being quick to affix blame, significant others may be more willing to overlook and even downplay any part the stressed person may have played in bringing about his or her problem. Moreover, support providers may be less critical of failed coping efforts when the precipitating event arises in a highly salient role. In fact, Taylor and Brown (1988) argue that stressed individuals may selectively seek out this type of support provider in an effort to restore their battered sense of self-worth. Regardless of who initiates the support process, the key point is that the stress-buffering properties of supportive social ties may be greatly enhanced when those giving assistance avoid being critical and focus instead on expressing concern and providing reassurance.

Taken as a whole, this brief theoretical overview begins to more clearly sketch out the conditions under which assistance will be sought, why older adults may be especially motivated to make the most of this support once it has been provided, and how this assistance may serve to bolster feelings of personal control and self-worth. This theoretical perspective is more consistent with the emerging view of the social support process as a tenuous balance between concern and resentment as well as dependence and self-assertedness. More important, this conceptual overview leads to the following study hypotheses:

1. Social support will reduce the deleterious effects of salient role stressors by bolstering feelings of personal control and these effects will be especially evident when role-specific measures of personal control are examined. In contrast, assistance from others will be less effective in reducing the impact of stressors that arise in roles that are valued less highly.

2. Social support will reduce the negative impact of salient role stressors by enhancing feelings of self-worth and these benefits will be especially strong when role-specific measures of self-esteem are used. However, assistance from significant others will be less likely to buffer the effects of events in less important roles. 


\section{Methods}

\section{SAMPLE}

The population for this study consisted of all household (i.e., noninstitutionalized) residents who were English-speaking, 65 years of age or older, and retired (i.e., not working for pay). Geographically, the study population was restricted to persons who live in the coterminous United States (i.e., residents of Alaska and Hawaii were excluded).

The sampling frame consisted of all eligible persons contained in the Health Care Finance Administration (HCFA) Medicare Beneficiary Eligibility List. This database contains the name, address, age, sex, and race of virtually every older adult in the United States. It should be emphasized that elderly people are included in this list even if they are not currently receiving social security benefits. There are, however, two groups of older adults who cannot be identified with this database-elderly people who do not have a social security number (this may occur because of illegal migration), and individuals who are 100 years of age or older (HCFA does not release the names of these people because of the error in self-reported age at this level).

The sample for this study was drawn with a three-stage process. First, $5 \%$ of the names in the nationwide file maintained by HCFA were selected with a simple random sampling procedure. Next, 110 counties across the coterminous United States were identified as primary sampling units (PSUs). These PSUs were selected with probability in proportion to the number of residents who were retired and at least 65 years of age. Following this, 10 persons residing in each PSU were selected from the HCFA list. Some counties (e.g., Dade County, Florida) were oversampled because they contain a disproportionately large number of eligible older adults.

The interviews were conducted by Lewis Harris and Associates between October 1992 and February 1993. A total of 1,103 interviews were completed successfully. The overall response rate for the study was $69.1 \%$. The average interview lasted 68.3 minutes $(S D=18.4$ minutes). After taking item nonresponse into account with the listwise deletion of missing values, complete data are available for 1,072 study participants. Approximately $40 \%$ of the elderly people in this group 
were men. The average age of the respondents was 74.2 years $(S D=$ 6.8 years). Finally, the older adults in this sample reported that they had successfully completed an average of 11.1 years of schooling $(S D=$ 3.4 years). All estimates presented in this report are based on weighted data.

\section{MEASURES}

The measures that were used to examine the relationships among stress, social support, personal control, and self-esteem are presented in Table 1. These indicators are described below.

Stressful life events. Based on procedures developed by Hoelter (1985), respondents were presented with a list of eight social roles: spouse; parent; grandparent; other relative; friend; homemaker; provider; and voluntary association, church, or club member. Initially, study participants were asked to identify the three roles that best reflect how they think about themselves. Following this, they were asked to rank order the selected roles according to whether they were first, second, or third most important. Although all study participants were able to select one role as being the most important to them, preliminary analyses reveal that $3.7 \%(n=41)$ of the respondents were unable to identify a second most important role, whereas an additional $7.4 \%(n=$ 82) did not select a third most important role (see Krause forthcoming a, for a detailed description of those study participants who did not select a second and third most important role).

Information on stressful life events was obtained with a 49-item checklist. Study participants were asked to indicate all of the stressors they had experienced in the year preceding the interview. In addition, they were asked to report whether the events that occurred were desirable or undesirable. Based on procedures developed by Krause (1986) and others, the stressors were grouped into eight domains that correspond to the eight social roles described above. This means, for example, that all events arising in the parental role were presented in the same section. As Stone, Kessler, and Haythornthwaite (1991) argue, this approach tends to facilitate recall because it allows study participants to think about one social role at a time, instead of skipping back and forth across multiple domains as is typically the case in most life event inventories. 
TABLE 1

Study Measures

1. Stressors arising in salient social roles

Number of undesirable events occurring in the most highly valued roles.

2. Stressors arising in roles that are valued less highly

Number of undesirable events occurring in nonsalient roles.

3. Emotional support rceived from others ${ }^{\mathrm{a}}$

A. During the past year, how often has someone been right there with you (physically) in a stressful situation?

B. How often has someone comforted you by showing you physical affection?

C. How often has someone listened to you talk about your private feelings?

D. How often has someone expressed interest and concern in your well-being?

4. Global feelings of control ${ }^{b}$
A. Becoming a success is a matter of hard work; luck has little or nothing to do with it.
B. In my case, getting what I want has little or nothing to do with luck.
C. It is impossible for me to believe that luck or chance plays an important role in my life.

5. Role-specific feelings of control ${ }^{c}$

A. Thinking about yourself as a (MOST SALIENT ROLE), select the number that comes closest to how you feel as a (MOST SALIENT ROLE).

Cannot influence

Can influence

what happens what happens
1
2
3
4
5

B. Please pick the number that comes closest to how you feel when you think of yourself as a (MOST SALIENT ROLE).

Cannot manage problems

Can manage problems that arise that arise

1 2 3 4 5

C. Which number best reflects how you think about yourself as a (MOST SALIENT ROLE)? Cannot make plans work 1 2 3 4 Can make plans work

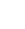

5

6. Global self-esteem ${ }^{b}$
A. I feel that I'm a person of worth, or at least on an equal plane with others.
B. I feel that I have a number of good qualities.
C. I am able to do things as well as most other people.
D. I take a positive attitude toward myself.

7. Role-specific self-esteem ${ }^{c}$
A. Thinking about yourself as a (MOST SALIENT ROLE), select the number that comes closest to how you feel as a (MOST SALIENT ROLE). Useless 
TABLE 1: Continued

7. Role-specific self-esteem ${ }^{c}$

B. Please pick the number that comes closest to how you feel when you think of yourself as a (MOST SALIENT ROLE).

Worthless

Worthwhile

1

2

3

4

5

C. Which number comes closest to how you think about yourself as a (MOST SALIENT ROLE)?

Unsuccessful

Successful

1

2

3

4

5

a. These variables are scored in the following manner (coding in parentheses): very often (4); fairly often (3); once in a while (2); never (1).

b. These variables are scored in the following manner: agree strongly (5); agree somewhat (4); not sure (3); disagree somewhat (2); disagree strongly (1).

c. This series of items was repeated for each salient role identified by the respondent.

A second procedure that was developed by Krause (1986) and others was used to further enhance the accuracy of reporting stressful life events. It is impossible to devise a checklist that contains every stressor that could possibly arise in the lives of older adults. However, it is possible to pick up some of the events that might normally be missed by placing an open-ended probe at the end of each list of role-related stressors. This means, for example, that the section dealing with stressors arising in the parental role would conclude with an open-ended question that asks respondents whether anything else happened that involved their children. Study participants were encouraged to report up to three additional events.

Two separate stress measures were developed to test the main study hypotheses. The first reflects stressors arising in salient social roles, whereas the second assesses life events that emerge in roles that are valued less highly. The procedures used to devise these stress indexes are described briefly below.

According to the theoretical perspective discussed above, it may initially appear as though the best way to assess the impact of salient role stressors is to focus solely on the events arising in the one role that is most important to study participants. However, events arising in all the roles that were identified as important (i.e., a maximum of three) are used in the analyses presented below. There are two reasons for adopting this measurement strategy. First, it is unlikely that there is a substantial difference in importance among the roles that are clustered at the top of the salience hierarchy. For example, many (if 
not most) study participants are unlikely to feel that being a parent is substantially more important than being a spouse. If this is true, then focusing solely on stressors in the single most important role (e.g., the parental role only) may underestimate the impact of salient role stressors because events arising in the second and third most important roles would not be represented accurately in the analyses. This view is consistent with the classic work of McCall and Simmons (1966), who argue that role identities are not separate entities but instead mutually influence one another and are woven into a more or less systematically interrelated whole. The second reason for combining events in the three most salient roles has to do with the distribution of stressful life events in this sample. Consistent with previous studies of older adults (e.g., Krause 1986), the respondents in the present study did not experience a large number of stressful events. In fact, the average elderly person reported experiencing only 2.1 undesirable stressors across all eight roles combined, $S D=2.4$. Any attempt to partition this data into separate stress measures for each salient role would have produced highly skewed indicators with little variance. Consequently, the measure used in the analyses presented below represents the unweighted number of undesirable events arising in all of the salient roles taken together, $\bar{X}=.95 ; S D=1.37$; range $=0-10$. In contrast, the second measure stands for the unweighted sum of undesirable events in all remaining nonsalient roles combined, $\bar{X}=$ $1.17 ; S D=1.56 ;$ range $=0-8$. The decision to use the unweighted sum of undesirable events in these measures is based on extensive research with stressful life event coding schemes reported by Ross and Mirowsky (1979) (see also Stone et al. 1991).

Social support. Social support was measured with a brief index consisting of four items that were taken from the work of Krause and Markides (1990). These indicators ask older adults to report how often they have received emotional support from their significant others. A high score on this composite indicates more emotional support. The internal consistency reliability estimate for this measure is $\mathbf{8 8 5}$.

Although the literature indicates that support received from others can be measured in a number of different ways (e.g., tangible support, informational assistance), only emotional support will be examined in this study. In addition to the rationale presented earlier, there are three reasons for making this choice. First, research reviewed by House and 
Kahn (1985) indicates that the dimensions of received support are highly intercorrelated and that emotional support may form the core of this conceptual domain. The second reason has to do with the way stressors are measured in this study. Even though the life event checklist described above was disaggregated into salient and nonsalient events, the kinds of stressors emerging within any given role are still fairly diverse. For example, the parental role contains stressors ranging from the death of a child to an offspring moving out of state. It seems unlikely that the same type of assistance (e.g., tangible support) will be useful in coping with these markedly different events (e.g., a child moving out of state). In contrast, it appears as though emotional support may be useful in a wider range of situations. The final reason for examining only emotional support may be found in a recent review of the literature by Hobfoll and Vaux (1993). These investigators report that emotional support seems to be especially important for rebuilding feelings of control and self-worth.

Global feelings of personal control. As described in the data analysis plan that is presented below, two sets of analyses will be performed to highlight the importance of working with role-specific measures of control. The first set will be used to evaluate whether emotional support reduces the deleterious effects of stress on global or generalized feelings of control. These results will be contrasted with findings that are derived by estimating whether support reduces the noxious impact of stress on role-specific measures of control. As shown in Table 1, global or generalized feelings of control are assessed with three items that were taken from Rotter's (1966) I-E Scale. A high score on this measure denotes internal feelings of control. The reliability of this brief composite is 685 .

Domain-specific feelings of control. Table 1 contains a listing of the items that were used to measure feelings of control associated with the roles that are most important or salient for study participants. A series of three semantic differentials were used to evaluate feelings of control over each selected role. Because the same items were used to evaluate control in each role, the semantic differentials are listed only once in Table 1. A high score on these items stands for greater feelings of personal control.

As discussed above, the measure of stressors arising in salient social roles contains events that emerged in all salient roles combined. Given 
this measurement strategy, it was not possible to examine the impact of this stress measure on feelings of control for each salient role taken separately. To make the analyses more logically consistent, a more compatible index was developed by summing the measures of control over all salient roles taken together.

One way to determine whether this measurement strategy is justified is to examine the intercorrelations among the individual rolespecific measures of control. Low correlations among these measures would suggest that feelings of personal control vary substantially across salient life domains and that some other strategy must be found to examine role-specific feelings of personal control. A second-order factor model provides a sophisticated way of addressing this issue. This model provides two sets of coefficients (i.e., factor loadings). The first evaluates the relationship between the raw survey items shown in Table 1 and an unmeasured construct denoting control over each salient role taken separately. The second (and perhaps most important) set of estimates indicates how strongly these first-order assessments of control are, in turn, related to a higher-order construct representing control over all three salient roles taken together. As shown in data we have provided elsewhere, the average factor loading of the first-order role-specific measures of control on the higher-order control construct is .735 (see Krause forthcoming a). This finding suggests that there is a considerable amount of consistency in the extent to which elderly people feel that they can exercise control over the roles that are most important to them and that there is some justification for using an aggregate measure to examine feelings of control over the three most salient roles taken together.

There is, however, one caveat associated with this measurement approach. Because 123 subjects did not identify a second or third most important role, they were not presented with the full battery of rolespecific control measures. One strategy might be to estimate separate models for those identifying only one, two, or three salient roles. However, the number of respondents selecting only one $(N=41)$ or two $(N=82)$ salient roles is too small to permit this kind of analyses. The best alternative, and the one pursued here, involves restricting the analysis to the remaining group of study participants who identified three salient roles. After using listwise deletion of missing values to take the effects of item nonresponse into account, there were 958 cases 
available for the segment of the analyses involving the role-specific measures. The internal consistency reliability estimate for the measure assessing feelings of control across all three salient roles combined is .873 .

Global self-esteem. As shown in Table 1, global feelings of selfworth are measured with four indicators that were taken from the scale developed by Rosenberg (1965). These items are coded so that a high score reflects greater feelings of self-worth. The reliability of this brief composite is $\mathbf{. 7 5 8 .}$

Domain-specific measures of self-esteem. Following the procedures used to develop role-specific control measures, a series of semantic differential items were devised to evaluate feelings of selfworth that are associated with each salient role. These items are listed only once in Table 1 because the same set of indicators was used to assess feelings of self-worth in each selected role.

Consistent with the rationale provided above, a summary measure was created that reflects feelings of self-esteem that are associated with all salient roles taken together. Once again, a second-order factor model was estimated to make sure that this aggregate approach was justified (tables containing the results of these analyses are available upon request from the first-listed author). As discussed above, the key test is whether the first-order constructs representing feelings of self-worth associated with each salient role taken separately are related strongly to a higher-order construct denoting feelings of selfesteem over all salient roles combined. These additional analyses (not shown here) revealed that the average factor loading of the rolespecific measures of self-worth on the higher-order self-esteem construct is $\mathbf{8 1 1}$. These data indicate that feelings of self-worth tend to be quite consistent across the roles that are valued most highly by elderly people and that it is appropriate to proceed with the use of the cumulative measure of self-esteem. Finally, further analyses using the self-esteem data revealed that the internal consistency reliability estimate for this composite index is .916 .

Demographic control measures. To take the effects of population heterogeneity into account, the impact of age, sex, and education were controlled statistically. Age is coded as a continuous measure, sex is assessed with a binary measure $(1=$ males; $0=$ females $)$, and education is coded in a continuous format reflecting the total number of years of completed schooling. 


\section{Data Analysis Strategy}

One of the main hypotheses that is examined in this study stipulates that the impact of salient role stressors on feelings of personal control depends upon the amount of emotional support that is available. This specification denotes a statistical interaction effect because the impact of one independent variable (stress) on the outcome measure (control) is contingent upon the value of a second independent variable (support). The estimation of statistical interaction effects remains a controversial issue in the literature (Busemeyer and Jones 1983). No attempt will be made to resolve this debate here. Instead, tests for statistical interactions will be performed with ordinary least squares multiple regression equations that contain multiplicative or crossproduct terms. Throughout, these analyses will follow the data analytic procedures described by Aiken and West (1991). More specifically, all measures (except the dependent variables) were centered (i.e., put in deviation score form), and the formulas provided by these investigators were used to assess the effects of stress on control and esteem at selected values of emotional support.

To highlight the advantages of working within a role-specific perspective, the analyses were performed in two steps. First, estimates were obtained for the interaction between stress and social support on the global measure of control. Following this, the analyses were repeated after the global measure was replaced with the role-specific measure of control described above. Identical procedures were used to estimate the interaction between stress and emotional support on the self-esteem measures.

Results

\section{STRESS, SUPPORT, AND PERSONAL CONTROL}

The results involving global feelings of control are presented in the left-hand portion of Table 2. The first column contains the additive effects of the stress and social support measures whereas the second column contains the findings that emerged when cross-product terms were added to the equation to test for the hypothesized interaction effects. 
TABLE 2

Stress, Emotional Support, and Feelings of Personal Control

\begin{tabular}{|c|c|c|c|c|}
\hline \multirow[b]{2}{*}{ Independent Variable } & \multicolumn{2}{|c|}{$\begin{array}{c}\text { Global Feelings } \\
\text { of Controt }^{\mathrm{a}}\end{array}$} & \multicolumn{2}{|c|}{$\begin{array}{c}\text { Role-Specific } \\
\text { Feelings of Control }\end{array}$} \\
\hline & $\begin{array}{c}\text { Additive } \\
\text { Model }\end{array}$ & $\begin{array}{c}\text { Interactive } \\
\text { Model }\end{array}$ & $\begin{array}{c}\text { Additive } \\
\text { Model }\end{array}$ & $\begin{array}{c}\text { Interactive } \\
\text { Model }\end{array}$ \\
\hline Age & $\begin{array}{c}.023^{c} \\
(.010)^{d}\end{array}$ & $\begin{array}{l}.020 \\
(.009)\end{array}$ & $\begin{array}{l}-.169 * \\
(-.191)\end{array}$ & $\begin{array}{l}-.168 * \\
(-.190)\end{array}$ \\
\hline Sex & $\begin{array}{l}-.005 \\
(-.028)\end{array}$ & $\begin{array}{l}-.003 \\
(-.021)\end{array}$ & $\begin{array}{c}.056 \\
(.842)\end{array}$ & $\begin{array}{c}.050 \\
(.754)\end{array}$ \\
\hline Education & $\begin{array}{l}-.036 \\
(-.031)\end{array}$ & $\begin{array}{l}-.035 \\
(-.031)\end{array}$ & $\begin{array}{c}.024 \\
(.052)\end{array}$ & $\begin{array}{c}.024 \\
(.053)\end{array}$ \\
\hline Salient stressors & $\begin{array}{c}-.083^{*} \\
(-.183)\end{array}$ & $\begin{array}{c}-.073^{*} \\
(-.160)\end{array}$ & $\begin{array}{l}-.118^{*} \\
(-.618)\end{array}$ & $\begin{array}{c}-.134^{*} \\
(-.701)\end{array}$ \\
\hline Nonsalient stressors & $\begin{array}{c}.011 \\
(.021)\end{array}$ & $\begin{array}{c}.017 \\
(.032)\end{array}$ & $\begin{array}{l}-.011 \\
(-.053)\end{array}$ & $\begin{array}{l}-.0001 \\
(-.002)\end{array}$ \\
\hline Emotional support & $\begin{array}{c}.051 \\
(.042)\end{array}$ & $\begin{array}{c}.047 \\
(.038)\end{array}$ & $\begin{array}{c}.079 * \\
(.160)\end{array}$ & $\begin{array}{c}.081^{*} \\
(.163)\end{array}$ \\
\hline Salient $\times$ Support & - & $\begin{array}{l}-.039 \\
(-.024)\end{array}$ & $\begin{array}{l}- \\
-\end{array}$ & $\begin{array}{l}.091^{*} \\
(.131)\end{array}$ \\
\hline Nonsalient $\times$ Support & - & $\begin{array}{c}-.027 \\
(-.014)\end{array}$ & - & $\begin{array}{c}-.076^{*} \\
(-.101)\end{array}$ \\
\hline
\end{tabular}

a. $N=1,072$.

b. $N=958$.

c. Standardized regression coefficient.

d. Unstandardized (metric) regression coefficient.

${ }^{*} p<.05$.

As reported by Krause (forthcoming a), the data in the first column of Table 2 suggest that stressors arising in salient social roles tend to erode global feelings of control, $\beta=-.083, p<.01$, whereas events that emerge in roles that are valued less highly fail to exert a significant effect, $\beta=.011$, not significant. Perhaps more important, the tests for statistical interaction effects reported in column 2 indicate that emotional support does not appear to reduce the deleterious effects of stressors arising in either salient $(b=-.024, n . s$.) or nonsalient $(b=$ -.014 , n.s.) social roles.

If control had been assessed solely with global measures, then the findings presented above would lead to the conclusion that emotional support does not replenish feelings of control that have been eroded by stressful events. However, as the results presented below will reveal, the opportunity to gain some valuable insights into the stress 
process would have been missed by following this conventional measurement strategy.

Two potentially important findings emerge from the data presented in the third column of Table 2. First, as reported by Krause (forthcoming a), stressors arising in salient roles tend to diminish role-specific feelings of control, $\beta=-.118, p<.01$, whereas stressors associated with roles that are valued less highly have virtually no effect, $\beta=-.011$, n.s. Second, the data in column 3 further indicate that irrespective of the amount of stress that is present, greater emotional support is associated with increased role-specific feelings of control, $\beta=.079$, $p<.01$. Because a comparable effect was not present when global feelings of control were examined (see column 1), these modest findings seem to suggest that emotional support may serve a more specialized function than has previously been described in the literature. This point becomes even more evident when the interaction effects presented in column 4 are reviewed and interpreted.

The data in column 4 reveal that the interaction between salient role stressors and emotional support on role-specific feelings of control is significant at the .01 level $(b=.131)$. In addition, the multiplicative term representing the interaction between emotional support and stressors in less highly valued roles is also statistically significant, but it is important to point out that the sign of this coefficient is in the opposite direction $(b=-.101)$.

Based on the data presented in Table 2, it may be somewhat difficult to determine the precise nature of these complex interaction effects. Fortunately, Aiken and West (1991) provide a series of formulas that can be used to clarify these effects by providing estimates of the impact of stress at selected levels of emotional support. The results of these additional computations are presented in Table 3.

Consistent with the stress-buffering hypothesis proposed above, the data in Panel A of Table 3 suggest that stressors arising in salient social roles tend to exert a fairly substantial effect on role-specific feelings of control among those elderly people who receive the least emotional support, $\beta=-.302, p<.001$. However, the data further reveal that the noxious effects of salient role stressors begin to decline steadily as the level of emotional support provided by others increases. At one standard deviation below the mean emotional support value, the impact of salient roles stressors declines by about $25 \%, \beta=-.226, p<$ 
TABLE 3

Impact of Stressor on Role-Specific Control at Selected Values of Emotional Support $(N=958)$

Panel A. Stressors in Salient Roles

Lowest observed support score $-.302 *$

-1 Standard deviation $(-1.582)^{b}$

$-.226^{*}$

$(-1.181)$

Mean support value

$-.134^{*}$

$(-.701)$

+1 Standard deviation

$-.042$

$(-.222)$

Highest observed support score

$-.002$

(-.010)

Panel B. Stressors in Nonsalient Roles

Lowest observed support score

- 1 Standard deviation

Mean support value

$(-.002)$

+1 Standard deviation

$-.078$

$(-.375)$

Highest observed support score

a. Standardized regression coefficient.

b. Unstandardized (metric) regression coefficient. ${ }^{*} p>.05$.

.001 . This effect is reduced by an additional $41 \%$ for elderly people with mean levels of emotional support, $\beta=-.134, p<.001$. It is especially important to note that at one standard deviation above the mean support value, the deleterious effects of stressors arising in salient social roles are offset completely, $\beta=-.042$, not significant.

The data in Panel B of Table 3 also help to clarify the meaning of the negative coefficient for the interaction between nonsalient stressors and emotional support. More specifically, these findings reveal that instead of reducing the negative impact of stress, greater amounts of emotional support seem to actually exacerbate the negative effects of stressors arising in roles that are valued less highly. This finding was not anticipated. Consequently, any post hoc explanation must be viewed with caution. Even so, a careful re-examination of the data in Panel B points to one intriguing possibility. As these data reveal, 
significant findings emerge only for those older adults with very high levels of emotional support-at the highest observed level of emotional support, stressors in nonsalient roles tend to erode role-specific feelings of personal control, $\beta=-.113, p<.05$.

Perhaps receiving a great deal of assistance for problems that are relatively unimportant tends to create feelings of dependence that may be accompanied by a diminished sense of personal control. Although this interpretation cannot be evaluated with the available data, it is consistent with findings from a longitudinal study by Krause (1987c), which suggests that very high levels of emotional support tend to diminish generalized feelings of control through time.

Taken as a whole, the findings in this section suggest that assistance from others is most beneficial when it is used to confront life events that arise in roles that are valued highly. In contrast, emotional support appears to offer few advantages (and may even be detrimental) for elderly people who are confronted by stressors in roles that are less salient. Because the significant findings were largely restricted to role-specific (but not global) feelings of control, these results serve to underscore the importance of looking for the effects of life events in the roles in which these stressors emerged. The findings presented in the next section further substantiate this more focused orientation by suggesting that salient role stressors and emotional support may play a similar role in shaping feelings of self-worth in later life.

\section{STRESS, EMOTIONAL SUPPORT, AND SELF-ESTEEM}

Data on the relationships among stress, emotional support, and global feelings of self-esteem are presented in the left-hand panel of Table 4. Two main findings emerge from this portion of the table. First, and perhaps most important, the tests for statistical interaction effects reveal (see column 2) that emotional support does not appear to buffer the effects of either salient ( $b=-.023$, n.s.), or nonsalient role stressors ( $b=-.005$, n.s.), on global feelings of self-worth. Second, whereas salient role stressors do not exert significant additive effects on global self-esteem, $\beta=-.017$, not significant, events arising in roles that are valued less highly appear to have a modest but statistically significant impact, $\beta=-.074, p<.05$. Taken at face value, these findings would appear to indicate that social support is not an effective 
TABLE 4

Stress, Emotional Support, and Self-Esteem

\begin{tabular}{|c|c|c|c|c|}
\hline \multirow[b]{2}{*}{ Independent Variable } & \multicolumn{2}{|c|}{$\begin{array}{l}\text { Global Feelings } \\
\text { of Self-Esteem }^{\mathrm{a}}\end{array}$} & \multicolumn{2}{|c|}{$\begin{array}{c}\text { Role-Specific } \\
\text { Feelings of Self-Esteem }^{b}\end{array}$} \\
\hline & $\begin{array}{l}\text { Additive } \\
\text { Model }\end{array}$ & $\begin{array}{l}\text { Interactive } \\
\text { Model }\end{array}$ & $\begin{array}{l}\text { Additive } \\
\text { Model }\end{array}$ & $\begin{array}{l}\text { Interactive } \\
\text { Model }\end{array}$ \\
\hline Age & $\begin{array}{l}-.060^{c} * \\
(-.119)^{d}\end{array}$ & $\begin{array}{l}-.062^{*} \\
(-.021)\end{array}$ & $\begin{array}{l}-.120^{*} \\
(-.113)\end{array}$ & $\begin{array}{l}-.119^{*} \\
(-.111)\end{array}$ \\
\hline Sex & $\begin{array}{l}-.029 \\
(-.135)\end{array}$ & $\begin{array}{l}-.028 \\
(-.127)\end{array}$ & $\begin{array}{c}-.052 \\
(.643)\end{array}$ & $\begin{array}{l}-.056 \\
(-.701)\end{array}$ \\
\hline Education & $\begin{array}{l}.156^{*} \\
(.103)\end{array}$ & $\begin{array}{l}.157^{*} \\
(.104)\end{array}$ & $\begin{array}{l}.083^{*} \\
(.153)\end{array}$ & $\begin{array}{c}.083^{*} \\
(.153)\end{array}$ \\
\hline Salient stressors & $\begin{array}{l}-.017 \\
(-.028)\end{array}$ & $\begin{array}{l}-.004 \\
-.007)\end{array}$ & $\begin{array}{c}-.072 * \\
(-.315)\end{array}$ & $\begin{array}{l}-.087^{*} \\
(-.378)\end{array}$ \\
\hline Nonsalient stressors & $\begin{array}{l}-.074^{*} \\
(-.106)\end{array}$ & $\begin{array}{l}-.070^{*} \\
(-.101)\end{array}$ & $\begin{array}{l}-.041 \\
(-.165)\end{array}$ & $\begin{array}{l}-.036 \\
(-.145)\end{array}$ \\
\hline Emotional support & $\begin{array}{c}.057 \\
(.035)\end{array}$ & $\begin{array}{c}.053 \\
(.033)\end{array}$ & $\begin{array}{l}.115^{*} \\
(.193)\end{array}$ & $\begin{array}{l}.118^{*} \\
(.197)\end{array}$ \\
\hline Salient $\times$ Support & - & $\begin{array}{l}-.051 \\
(-.023)\end{array}$ & - & $\begin{array}{l}.077^{*} \\
(.092)\end{array}$ \\
\hline Nonsalient $\times$ Support & - & $\begin{array}{l}-.011 \\
(-.005)\end{array}$ & - & $\begin{array}{l}-.045 \\
(-.050)\end{array}$ \\
\hline
\end{tabular}

a. $N=1,072$

b. $N=958$

c. Standardized regression coefficient

d. Unstandardized (metric) regression coefficient

${ }^{*} p<.05$.

stress-buffering resource and that salient role stressors do not play a significant role in shaping feelings of self-worth in later life. However, as the data in columns 3 and 4 suggest, this may not be a valid conclusion.

The data in the right-hand portion of Table 4 reflects the impact of the stress measures and emotional support on role-specific feelings of self-esteem. Two of the additive effects shown in column 3 begin to provide a different picture of the stress process than emerged with the global measure of self-worth. First, the findings reveal that consistent with the theoretical orientation discussed above, stressors that arise in salient social roles tend to erode role-specific feelings of self-esteem, $\beta=-.072, p<.05$, whereas life events that arise in roles that are valued less highly fail to exert a similar effect, $\beta=-.036, \mathrm{n} . \mathrm{s}$. Second, the data indicate that after the effects of both stress measures have been 
controlled statistically, more emotional support is associated with increased feelings of self-worth, $\beta=.115, p<.001$. Once again, the fact that emotional support is related to the role-specific (but not the global) measures of self-esteem speaks to the emerging view that the effects of assistance provided by others may be more evident in the areas of life that are valued most highly by older adults. Further support for this conceptual orientation may be found in column 4, where the results from the tests for statistical interaction effects are reported.

As the data in column 4 reveal, emotional support appears to buffer the noxious effects of stressors arising in salient social roles $(b=.077$, $p<.05$ ), but not the impact of life events that emerge in roles that are valued less highly $(b=-.045$, n.s.). Following the procedures that were used in the previous section, the formulas provided by Aiken and West (1991) were used to specify the nature of this interaction effect more clearly. The results of these computations are presented in Table 5.

The data in Table 5 suggest that at the lowest observed emotional support score, stressors in salient social roles tend to exert the strongest impact on role-specific feelings of self-esteem, $\beta=-.230, p<.01$. However, consistent with the classic stress-buffering model, these negative effects decline steadily as the amount of emotional support provided to elderly people increases. More specifically, at one standard deviation below the mean support value, the effects of salient roles stressors drop to $-.165, p<.01$, whereas the stress-buffering effects become even more pronounced at the mean emotional support value, $\beta=-.087, p<.05$. Perhaps more important, the data in Table 5 suggest that the noxious effects of salient role stressors are offset completely for those elderly people who receive more than average levels of emotional support. For example, at one standard deviation above the mean value, the effects of stressors in salient roles on role-specific feelings of self-esteem are no longer statistically significant, $\beta=-.009$, n. s.

Taken together, the findings presented in this section suggest that emotional support is an efficacious coping resource that is helpful for confronting salient role stressors but not events emerging in less highly valued roles. Perhaps more important, these effects are only evident when role-specific measures of self-esteem are examined and not 
TABLE 5

Impact of Salient Role Stressors on Role-Specific

Self-Esteem at Selected Values of Emotional Support $(N=958)$

$\begin{array}{cc}\text { Lowest observed support score } & -.230^{* *} \\ \text { - } 1 \text { Standard deviation } & (-1.003)^{\mathrm{b}} \\ & -.165^{*} \\ \text { Mean support value } & (-.718) \\ & -.087^{*} \\ +1 \text { Standard deviation } & (-.378) \\ & -.009 \\ \text { Highest observed support score } & (-.038) \\ & .026 \\ \end{array}$

a. Standardized regression coefficient.

b. Unstandardized regression coefficient. ${ }^{*} p<.05$.

when global measures of self-worth are used. The fact that emotional support has significant additive as well as interactive effects suggests that more than one mechanism may be at work and that this doublebuffering effect may enhance feelings of self-esteem through more than one pathway (see Wheaton 1985 for a detailed discussion of this issue).

\section{Conclusions}

In his cogent review of the literature, Antonovsky (1990, p. 75) facetiously points out that we are now in an era where social support has become, "the answer to everything." Although this view is a bit overstated, one does indeed get the impression that supportive social relationships always help elderly people to cope effectively with an almost unlimited range of problems and difficulties. Recognizing the oversimplified nature of this prevailing view, the intent of the present study has been to present a more circumscribed perspective by specifying the conditions under which support may be beneficial and by suggesting how these salubrious effects may be manifest. This aim is reflected in the two main findings that have emerged from this study. First, the data suggest that although emotional support may help elderly people cope with the effects of stressors that arise in salient roles, it appears to be less useful for dealing with events that emerge 
in roles that are valued less highly. Second, the findings further reveal that supportive social relations may operate, at least in part, by replenishing feelings of control and self-worth. However, these effects are evident only when measures are used that capture feelings of control and self-worth that are associated with the roles in which the salient stressors arose.

In the process of developing this more focused approach, an effort was made to provide a theoretical rationale for extending and merging recent developments in identity theory with more sophisticated conceptualizations of the structure of personal control and feelings of self-worth. All of the constructs that were invoked in this theoretical scheme were not measured or evaluated directly. Nevertheless, this conceptual orientation begins to provide a mechanism for integrating into a single framework a number of recently emerging findings that have tended to create a disjointed picture of the social support process. For example, a number of investigators have argued that social contact may involve negative interaction as well as supportive behaviors (e.g., Rook 1984). However, the conditions under which these negative encounters arise has not been specified clearly. One promising line of research might be to evaluate whether emotional support is accompanied by negative interaction (e.g., criticism) when older adults request or receive assistance for dealing with stressors that arise in nonsalient roles.

Those who wish to continue working along the lines developed in this study should address some of the limitations in this work. Six shortcomings will be discussed below. First, the analyses should be expanded to include a wider range of stressful experiences. Second, not all life events can be classified as arising in either salient or nonsalient roles. Third, the measures of control and self-esteem can be improved. Fourth, problems arise because the data used in this study are cross-sectional. Fifth, certain coping strategies may influence whether an older adult may identify a given role as salient. Finally, the theoretical scheme developed above is in need of further elaboration and refinement.

The analyses presented in this study deal solely with discrete life events. However, this does not exhaust the range of stressful experiences that may be encountered in social roles. For example, research by Pearlin and his associates suggests that persistent or ongoing 
difficulties (i.e., chronic role strains) may be an especially potent form of stress. These findings suggest that it may be useful to expand the scope of inquiry to include this potentially important type of stressor.

Older adults often encounter life events that do not fit neatly into the conceptual framework developed here (i.e., salient and nonsalient role stressors). For example, physical illness does not arise within a specific role per se, but it obviously can exert a deleterious effect in later life. As Thoits (1991) points out, this serves to underscore the notion that the perspective developed in the present study is not an all-encompassing scheme and that it refers instead to a potentially important subset of events. Nevertheless, researchers should consider taking a more comprehensive approach by simultaneously assessing the impact of salient role stressors, events arising in nonsalient roles, and stressors that arise outside of specific roles per se.

The global measures of control and self-esteem that are examined in this study were included primarily because they have been used frequently in previous research. The intent of this strategy was to show how more focused measures improve upon prior studies by contrasting the newly developed role-specific measures with these global indicators. However, this approach has a potential disadvantage that should be identified explicitly. An example should help to clarify the nature of this problem. The global control items refer largely to beliefs about the role that luck plays in life. In contrast, the role-specific measures of control deal with the perceived ability to manage problems and make plans work.

Because these items are not phrased in the same manner, it is difficult to tell whether the findings that were observed when using role-specific measures are due to differences in the way these items are phrased or whether the results reflect true advantages in working with role-specific measures. Those who wish to test the benefits of working with role-specific measures of control in the future would be well advised to contrast items that are more similar in phrasing and content.

The data in this study were gathered at a single point in time. Consequently, the temporal ordering among the key study constructs is based on theoretical considerations alone. For example, the analyses presented in this study are based on the assumption that social support 
tends to bolster feelings of control, but one could just as easily maintain that older adults with strong internal feelings of control are subsequently able to use their social support networks more effectively than elderly people who feel that they exert little influence over their environment (Sandler and Lakey 1982). Clearly, this as well as other causal assumptions that are embedded in the present study should be subjected to rigorous empirical evaluation with data that have been gathered at more than one point in time.

The utility of focusing on salient role stressors hinges on the ability or willingness of study participants to identify the social roles they value most highly. However, research reviewed by Hobfoll (1989) suggests that some people may attempt to cope with a loss in a highly valued domain by devaluing the importance of the role in which the stressor emerged. In fact, Moos and Schaefer (1986) refer to this coping response as a cognitive redefinition strategy. There are, however, two reasons why this may not be a major problem. The first may be found in extensive discussion of identity theory that is provided by McCall and Simmons (1966). They argue that the salience hierarchy is not that fluid and that the defense mechanism described by Hobfoll (1989) is likely to be a temporary reaction that fades in a matter of days. The second reason why cognitive redefinition coping strategies may not have affected the findings in the present study may be found in research by Krause and Baker (1992). This research reveals that the impact of financial difficulties on well-being is contingent on whether older adults value economic success highly. As part of this investigation, these researchers evaluated whether those who experience financial problems tend to downplay or devalue the importance of economic success. Krause and Baker (1992) were unable to find any evidence that this was the case. Nevertheless, additional work is needed to see whether cognitive redefinition coping strategies are being used in response to other types of stressful events.

Although the model that is examined in this study may provide some useful insights into the functions provided by supportive social relationships in later life, it should be emphasized that all of the relevant causal mechanisms that may be at work have not been identified. More specifically, the model discussed above specifies that stress operates by eroding feelings of control and self-esteem, yet it is evident that this may not be the case for every kind of stressful 
experience. For example, it is unlikely that self-esteem will be diminished when a loved one experiences a serious illness. Even so, social support is still an efficacious resource for dealing with this type of stressor. This suggests that supportive social ties must perform functions other than the ones that have been identified here, and that it is important to identify and examine these additional mechanisms.

Any attempt to examine a relatively unexplored area is bound to raise as many questions as it answers and create as many problems as it solves. This is certainly true of the work presented here. It is for this reason that the limitations in this study were discussed at length. Perhaps the real contribution of this type of research may be measured by the reflection that it promotes and the discussion that it sparks in the larger scientific community. Maybe the theoretical issues and empirical findings presented in this report will add to this ongoing process by providing a useful vantage point for examining the role played by supportive social relationships in later life.

\section{REFERENCES}

Aiken, Leona S. and Stephen G. West. 1991. Multiple Regression: Testing and Interpreting Interactions. Newbury Park, CA: Sage.

Antonovsky, Aaron. 1990. "A Somewhat Personal Odyssey in Studying the Stress Process." Stress Medicine 6:71-80.

Bengtson, Vern L., Margaret N. Reedy, and Chad Gordon. 1985. "Aging and Self-Conceptions: Personality Processes and Social Contexts." Pp. 544-93 in Handbook of the Psychology of Aging, edited by James E. Birren and K. Warner Schaie. New York: Van Nostrand Reinhold.

Burke, Peter J. 1991. "Identity Process and Social Stress." American Journal of Sociology 56:836-49.

Busemeyer, Jerome R. and Lawrence E. Jones. 1983. “Analysis of Multiplicative Combination Rules When the Causal Variables are Measured With Error." Psychological Bulletin 93:549-62.

Caplan, Gerald. 1981. "Mastery of Stress: Psychosocial Aspects." American Journal of Psychiatry 138:413-20.

Eckenrode, John and Elaine Wethington. 1990. "The Process and Outcome of Mobilizing Social Support." Pp. 83-103 in Personal Relationships and Social Support, edited by Steve Duck. Newbury Park, CA: Sage.

George, Linda K. 1989. "Stress, Social Support, and Depression Over the Life Course." Pp. 241-67 in Aging, Stress, Social Support and Health, edited by Kyriakos S. Markides and Cary L. Cooper. London: Wiley.

Hobfoll, Stevan E. 1989. "Conservation of Resources: A New Attempt at Conceptualizing Stress." American Psychologist 44:513-24. 
Hobfoll, Stevan E. and Alan Vaux. 1993. "Social Support: Resources and Context." Pp. 685-705 in Handbook of Stress: Theoretical and Clinical Aspects, edited by Leo Goldberger and Shlomo Breznitz. New York: Free Press.

Hoelter, Jon. 1985. "The Structure of Self-Conception: Conceptualization and Measurement." Journal of Personality and Social Psychology 49:1392-1407.

House, James S. and Robert L. Kahn. 1985. "Measures and Concepts of Social Support." Pp. 83-108 in Social Support and Health, edited by Sheldon Cohn and S. Leonard Syme. New York: Academic Press.

Krause, Neal. 1986. "Social Support, Stress, and Well-Being Among Older Adults." Journal of Gerontology 41:512-19.

Krause, Neal. 1987a. "Life Stress, Social Support, and Self-Esteem in an Elderly Population." Psychology and Aging 2:349-56.

Krause, Neal. 1987b. "Chronic Strain, Locus of Control, and Distress in Older Adults." Psychology and Aging 2:375-82.

Krause, Neal. 1987c. "Understanding the Stress Process: Linking Social Support with Locus of Control Beliefs." Journal of Gerontology 42:589-93.

Krause, Neal. 1989. "Issues of Measurement and Analysis in Studies on Social Support, Aging, and Health." Pp. 43-66 in Aging, Stress, Social Support, and Health, edited by Kyriakos S. Markides and Cary L. Cooper. London: Wiley.

Krause, Neal. 1991. "Stress and Isolation from Close Ties in Later Life." Journal of Gerontology: Social Sciences 46:S183-94.

Krause, Neal. Forthcoming a. "Stressors in Salient Social Roles and Well-Being in Later Life." Journal of Gerontology: Psychological Sciences.

Krause, Neal. Forthcoming b. "Stress and Diabetes Mellitus in Later Life." International Journal of Aging and Human Development.

Krause, Neal and Elizabeth Baker. 1992. "Financial Strain, Economic Values, and Somatic Symptoms in Later Life." Psychology and Aging 7:4-14.

Krause, Neal and Jersey Liang. Forthcoming. "Stress, Social Support, and Distress Among the Chinese Elderly." Journal of Gerontology: Psychological Sciences.

Krause, Neal and Kyriakos S. Markides. 1990. "Measuring Social Support Among Older Adults." International Journal of Aging and Human Development 30:37-53.

La Gaipa, John J. 1990. "The Negative Effects of Informal Support Systems." Pp. 122-39 in Personal Relationships and Social Support, edited by Steve Duck. Newbury Park, CA: Sage.

Lee, Gary R. 1985. "Kinship and Social Support of the Elderly: The Case of the United States." Ageing and Society 5:19-38.

McCall, George J. and J. L. Simmons. 1966. Identities and Interactions. New York: Free Press.

Moos, Rudolf H. and Jeanne A. Schaefer. 1986. "Life Transitions and Crises: A Conceptual Overview." Pp. 3-28 in Coping With Life Crises: An Integrated Approach, edited by Rudolf H. Moos. New York: Plenum.

Pearlin, Leonard I., Elizabeth Menaghan, Morton Lieberman, and John Mullan. 1981. "The Stress Process." Journal of Health and Social Behavior 22:337-56.

Rook, Karen S. 1984. "The Negative Side of Social Interaction: Impact on Psychological Well-Being." Journal of Personality and Social Psychology 46:1097-1108.

Rosenberg, Morris. 1965. Society and the Adolescent Self-Image. Princeton, NJ: Princeton University Press.

Ross, Catherine and John Mirowsky. 1979. "A Comparison of Life Event Weighting Schemes: Change, Undesirability, and Effect-Proportional Indices." Journal of Health and Social Behavior 20:166-77.

Rotter, Julian B. 1966. "Generalized Expectancies for Internal Versus External Control of Reinforcement." Psychological Monographs: General and Applied 80:1-28. 
Sandler, Irwin N. and Brian Lakey. 1982. "Locus of Control as a Stress Moderator: The Role of Control Perceptions and Social Support." American Journal of Community Psychology 10:65-80.

Schulz, Richard, Julian Heckhausen, and Julie L. Locher. 1991. "Adult Development, Control, and Adaptive Functioning." Journal of Social Issues 47:177-96.

Stone, Arthur A., Kessler, Ronald C., and Jennifer A. Haythornthwaite. 1991. "Measuring Daily Events and Experiences: Decisions for the Researcher." Journal of Personality 59:575-607.

Stryker, Sheldon. 1987. "Identity Theory: Developments and Extensions." Pp. 83-103 in Self and Identity: Psychosocial Perspectives, edited by Krysia Yardley and Terry Honess. New York: Wiley.

Taylor, Shelley E. and Jonathan D. Brown. 1988. "Illusion and Well-Being: A Social Psychological Perspective on Mental Health." Psychological Bulletin 103:193-210.

Thoits, Peggy A. 1987. "Gender and Marital Status Differences in Control and Distress: Common Versus Unique Stress Explanations." Journal of Health and Social Behavior 28:7-22.

Thoits, Peggy A. 1991. "On Merging Identity Theory and Stress Research." Social Psychology Quarterly 54:101-12.

Wheaton, Blair. 1985. "Models of the Stress-Buffering Functions of Coping Resources." Journal of Health and Social Behavior 26:352-64.

Neal Krause is Professor in the School of Public Health and Research Scientist in the Institute of Gerontology at the University of Michigan. He is currently working on projects that examine issues in the measurement of social support (funding provided by NIA), the relationship between stress and well-being (funding provided by NIA), and cross-cultural issues in aging (directed by Jersey Liang, funding provided by NIA).

Elaine Borawski-Clark is currently an NIA Postdoctoral Fellow in the Institute of Gerontology at the University of Michigan. Her current areas of interest include stress, health and aging, meaning of subjective health measurement, and social integration among the elderly. 